\title{
Characterization of the glycosylation profile of the human breast cancer cell line, MDA-231, and a bone colonizing variant
}

\author{
JAIME CARCEL-TRULLOLS ${ }^{1}$, JOSEPH S. STANLEY ${ }^{1}$, RINKU SAHA ${ }^{1}$, SAEID SHAAF$^{1}$, MANALI S. BENDRE $^{2}$, \\ BEHJATOLAH MONZAVI-KARBASSI ${ }^{1}$, LARRY J. SUVA ${ }^{2}$ and THOMAS KIEBER-EMMONS ${ }^{1}$ \\ ${ }^{1}$ Arkansas Cancer Research Center and Department of Pathology, University of Arkansas for Medical Sciences, \\ Little Rock, AR 72205; ${ }^{2}$ Center for Orthopaedic Research, Department of Orthopaedic Surgery, \\ University of Arkansas for Medical Sciences, Little Rock, AR 72205, USA
}

Received November 30, 2005; Accepted January 3, 2006

\begin{abstract}
The mechanisms that guide organ-specific metastases are not fully established. The aberrant expression of carbohydrates may play a fundamental role in defining the molecular mechanisms for metastases to distant organs and facilitate positive interactions within the target organ. The purpose of the present study was to determine the glycomic profile of a variant of the MDA-MB-231 breast cancer cell line that colonizes the bone and to ascribe mechanistic functions mediated by carbohydrates that might correlate with clinical bone metastases. The carbohydrate expression profiles of osteolytic MDA-MET breast cancer cells and non-osteolytic parental MDA-MB-231 cells were determined. MDA-MET cells were derived from MDA-MB-231 cells by in vivo selection of metastatic bone lesions following intracardiac inoculation. The two related breast cancer cell lines expressed distinct carbohydrate profiles; MDA-MET cells displayed an increased expression of alpha $(2,6)$ linked sialic acid, N-ß1-6 GlcNAc, and sialylated Lewis-A antigen, and decreased expression of Galß1,3GalNAc as detected using a combination of lectins and anti-carbohydrate antibodies. Microarray analysis demonstrated an increased expression of glycosyltransferase genes, correlative for the distinct glycomic phenotype. The altered glycomic phenotypes of MDA-MET cells include effects on the differential binding to bone marrow endothelial cells, enhanced ECM binding and an increase in invasive potential. These data suggest that the glycomic phenotype of MDA-MET cells is associated with a select set of accumulated functions that collectively impact on the bone metastases and bone colonization capacity of breast cancer cells.
\end{abstract}

Correspondence to: Dr Thomas Kieber-Emmons, Arkansas Cancer Research Center, University of Arkansas for Medical Sciences, 4301 West Markham, St. slot \#824, Little Rock, AR 72205, USA

E-mail: tke@uams.edu

Key words: osteolysis, organ tropism, osteotropism, glycomic phenotype

\section{Introduction}

Hematogenous and lymphatic spread of breast cancer cells can occur during an early stage of primary tumor growth (1). Alteration in the adhesion properties of neoplastic cells is perceived to play a pivotal role in the multi-step process that impacts on tumor cell-organ tropism and organ colonization $(2,3)$. A variety of factors, including the pattern of vascular flow from the primary site, complementary adhesive contacts, and molecular interactions between the tumor cell and the stroma at the secondary site dictates the selective distribution of metastases (2). Changes in cell-surface-expressed glycosylation patterns that affect adhesion are a universal characteristic of transformed cells that may also impact on organ tropism and/or organ colonization (4). Prominent among these tumor-related terminal structures are sialyl Lewis $X(\operatorname{sLeX}, \operatorname{NeuAc}(2,3)$ $\operatorname{Gal}(1,4)[\mathrm{Fuc}(1,3)] \mathrm{GlcNAc})$, sialyl Lewis A (sLeA, NeuAc(2,3) $\operatorname{Gal}(1,3)[\mathrm{Fuc}(1,4)] \mathrm{GlcNAc})$, the mucin-type core carbohydrates of Thomsen-Friedenreich $(\mathrm{T})$ antigen Galß1,3GalNAc, Tn antigen GalNAc-Thr/Ser, and $\beta 1,6$ GlcNAc branched products of $\mathrm{N}$ acetylglucosaminyltransferase $\mathrm{V}$ (GnT-V) (5). These particular determinants are intimately involved in hematogenous metastasis and tumor angiogenesis (6) as endothelium-attached blood-born tumor cells are postulated to be the seeds of secondary tumors (7).

The organ-specific phenotype of tumor cells might be a result of selection in both the bloodstream and the metastatic site. Early histochemical studies used tumor tissue to examine the hypothesis that primary carcinomas with metastases to different sites (lymph nodes or bone) show varying expression of cell-surface and cytoplasmic glycoconjugates (8). Primary tumors from patients with bone metastases but without lymph node involvement displayed significantly increased binding to lectins reactive with Galß1,3GlcNAc (Type 1 oligosaccharide structures) and Galß1,4GlcNAc (Type 2 oligosaccharide structures) compared with tumors from the lymph node-positive group (8). In vitro cell-binding studies suggest that the Type $3 \mathrm{~T}$ antigen structure facilitates homotypic binding of representative breast and prostate cancer cell lines and heterotypic binding to bone-marrow-derived endothelium cells, suggesting that this structure plays an important role in antigen-mediated tumor cell stromal adhesive interactions in metastatic bone disease $(9,10)$. 
Concomitantly, specific adhesive properties are mandatory for successful extravasation and invasion of the target tissue of metastatic cells. Transfection of tumor cells with glycosyltransferases provides further insight to the role of particular carbohydrate moieties, such as sialic acid, that affect the binding characteristics of extracellular matrix (ECM) components that may also impact bone metastases (11). Differential sialylation of the $\beta 1$ integrin chain (12) and differences in $\beta 1,6$ GlcNAc branching $(13,14)$ are observed to mediate collagen IV and fibronectin binding. Breast cancer cells that are dormant in the bone seem to prefer binding to fibronectin, and this binding appears to function as an anti-apoptotic signal (15). Consequently, differential ECM binding can impact stages of tumor colonization.

To assess the global glycomic phenotype associated with later stages of breast cancer bone metastasis, the carbohydrate surface expression profile of MDA-MB-231 (MDA-231) and an in vivo selected, bone colonizing, variant MDA-MET was evaluated. The MDA-MET cell line was selected in vivo from bone, following an intercardiac injection of MDA-231 cells, a process that was repeated four times (16). Staining with a variety of lectins and carbohydrate-reactive monoclonal antibodies, analysis of Western blots, and analysis of migration patterns, suggest a mechanistic importance of an increased level of expression of, B1-6 GlcNAc, and $\alpha 2,6$ sialylation on the surface of MDA-MET cells compared with MDA-231 cells. Decreased expression of Galß1,3GalNAc on MDA-MET cells is in concordance with increased sialylation products on MDA-MET cells. In concordance with the expectation that enhanced sialylation facilitates release of single cells from the primary tumor by reducing homotypic aggregation (17), we observed that MDA-MET cells displayed disaggregation properties with increased migration in wound assays. Also consistent with an increase in 2,6 sialylation, enhanced adhesion to collagen IV and the invasive properties of MDA-MET on Matrigel were observed. Interestingly, despite the enhanced sialylation products, cell surface lactosaminic termini still remain unsubstituted in MDA-MET cells suggesting that selective expression of Galß1,3GalNAc and B1-6 GlcNAc on MDA-MET cells are associated with proteins with particular functions, which may be responsible for selective interaction of MDA-MET cells with bone marrow endothelium cells or functionally important in the metastatic process. The present study provides supportive evidence that distal metastases are affected by complex relationships underlying coordinated changes in the expression of genes, production of proteins, and presentation of carbohydrate structures on cancer cell surfaces that influence tumor cell dissemination and, ultimately, bone colonization.

\section{Materials and methods}

Materials. Neuraminidase obtained from Vibrio cholerae was purchased from Sigma (St. Louis, MO), and was used at a concentration of $50 \mathrm{mU} / \mathrm{ml}$. The lectins, Agaricus bisporus (ABA), Helix pomatia (HPA), and MAA, were purchased from EY Laboratories, San Mateo, CA. The lectins, Amaranthus caudatus (ACL), Concanavalin A (Con A), Sambucus nigra (SNA), Erythrina cristagalli (ECA), Griffonia Simplicifolia (GS-I), Artocarpus integrifolia (Jacalin), Lotus tetragonolobus
(Lotus), Maclura pomifera (MPA), Phaseolus vulgaris (PHA), Arachis Hypogaea (PNA), Vicia villosa (VVA), and Triticum vulgaris (WGA), were purchased from Vector Laboratories, Burlingame, CA. The mAB, KM-93, was purchased from Kamiya Biomedical, Seattle, WA. FH6 and GSLA-2 were purchased from GlycoTech, Gaithersburg, MD. CSLEX was a kind gift from Dr John Magnani (GlycoTech Corporation). Rabbit anti-matriptase antibody was purchased from Bethyl, Inc., Montgomery, TX. Peroxidase-conjugated goat anti-rabbit IgG (A-6154), biotinylated goat anti-mouse $\operatorname{IgG}$ (B7022), and goat anti-mouse IgM (B9265) were purchased from Sigma.

Cell culture. The human breast cell line, MDA-MB-231 (MDA-231), was obtained from Dr Tom Kelly, University of Arkansas for Medical Sciences, Little Rock, AR. The MDAMET cell line was developed by in vivo selection of bone lesions after intracardiac inoculation of the MDA-231 cell line (16). The resulting cell line, MDA-MET, colonizes bone selectively (16) and, by secreting the chemokine interleukin 8 (IL-8), directly stimulates osteoclast differentiation and bone resorption (18). Both cell lines were maintained in Dulbecco's modified Eagle's medium (DMEM; Invitrogen Corp., Carlsbad, CA) supplemented with $10 \%$ fetal bovine serum (FBS) at $37^{\circ} \mathrm{C}$ in sterile culture flasks.

RNA purification and microarray hybridization and analysis. We performed gene array analysis using Affymetrix Gene Chips (Affymetrix, Santa Clara, CA) as described previously (16). Double-stranded cDNA and biotinylated cRNA were synthesized from total RNA (obtained from duplicate cultures of MDA-231 and MDA-MET cells) and hybridized to HuGeneFL GeneChip microarrays, which were washed and scanned according to the manufacturer's protocol. The arrays were scanned using a Hewlett Packard confocal laser scanner.

Microarray data bioinformatic analysis. The data were generated using Affymetrix 5.0 software (Affymetrix). The cell intensity file containing the average intensities of each cell generated by the software was utilized for further analysis by the open-source software Bioconductor (Release 1.2 Packages; http://www.bioconductor.org). Using the MAS methodology of Bioconductor (19), gene expression data was obtained after background correction, normalization, probe specific correction, and summary value computation. The MAS 5.0 program (Bioconductor) was used to produce gene expression values from the image intensity data. Statistically significant changes in gene expression were calculated using Student's t-test on the probe level intensity values; only levels of gene expression that were significantly different $(\mathrm{P}<0.05)$ were considered relevant.

Flow cytometric analysis. Cells were passaged $24 \mathrm{~h}$ before measuring lectin binding. The subconfluent monolayer of cells was detached using Cellstripper (Mediatech, Inc., Herndon, VA) and washed with Dulbecco's phosphate-buffered saline (DPBS) containing $\mathrm{Ca}$ and $\mathrm{Mg}$ (Mediatech, Inc., Herndon, VA). Cells were counted and diluted to $\sim 1-2 \times 10^{6}$ cells $/ \mathrm{ml}$. Biotinylated lectins were added to the cells at a final concentration of $5 \mu \mathrm{g} / \mathrm{ml}$ and monoclonal antibodies were added to a 
final concentration of $10 \mu \mathrm{g} / \mathrm{ml}$. Cells were incubated on ice for $30 \mathrm{~min}$ and washed twice with FACs buffer before adding fluorescein isothiocyanate (FITC)-conjugated streptavidin $(2 \mu \mathrm{g} / \mathrm{ml})$ for lectin analysis or FITC-conjugated goat antimouse immunoglobulin (1:60 dilution) for monoclonal analysis. Cells were then washed with FACS buffer and fixed with paraformaldehyde, before analysis by flow cytometry.

Lectin and Western blot analysis. Subconfluent monolayers of MDA-MET and MDA-231 cells were washed with PBS and lysed with sodium dodecyl sulfate (SDS) lysis buffer (4\% SDS, $125 \mathrm{mM}$ Tris- $\mathrm{HCl}, \mathrm{pH}$ 6.8). The protein concentration of the lysates was determined using the Bicinchoninic Acid (BCA) protein assay (Pierce, Rockford, IL). MDA-MET and MDA231 whole-cell lysates $(10 \mu \mathrm{g})$ were separated by SDS-PAGE on $10 \%$ polyacrylamide gel before electrotransfer to a Polyvinylidene fluoride (PVDF) membrane. The membrane was then blocked with BSA blocking buffer (DPBS with $9 \mathrm{mM}$ $\mathrm{CaCl}, 4.9 \mathrm{mM} \mathrm{MgCl}, 1 \% \mathrm{BSA}, 0.1 \%$ Tween $\mathrm{pH}$ 7.1) for at least $1 \mathrm{~h}$. The membranes were probed with $0.5 \mu \mathrm{g} / \mathrm{ml}$ of biotinylated lectin (except MAA, which was used at a concentration of $2 \mu \mathrm{g} / \mathrm{ml}$ ) or $0.5 \mu \mathrm{g} / \mathrm{ml}$ of affinity-purified rabbit anti-human matriptase diluted in BSA blocking buffer for $1 \mathrm{~h}$ at room temperature. The membranes were then washed and probed with streptavidin-conjugated horseradish peroxidase ( $2 \mu \mathrm{g} / \mathrm{ml}$ in BSA blocking buffer) or a 1:1000 dilution of peroxidase-conjugated goat anti-rabbit $\operatorname{IgG}$ for $1 \mathrm{~h}$ at room temperature. After washing, bound lectins were detected using SuperSignal West Pico Chemiluminescence substrate (Pierce) and Biomax autoradiographic film (Eastman Kodak Company, Rochester, NY).

Human bone marrow endothelial cells adhesion assay. Immortalized human bone marrow endothelial cells (TrHBMEC) were kindly provided by Drs D. Paulin (University of Paris VI), K. Schweitzer, and B.B. Weksler (both of Weill College of Medicine of Cornell University) (20-22). TrHBMEC were derived by immortalizing human bone marrow endothelial cells with a construct encoding the large T antigen of SV40 under the control of a truncated human vimentin promoter (22). The transformed cell line retained all of the characteristics of the untransformed cells, including expression of cell-surface markers (22).

Cells were grown on gelatin-coated plates in DMEM (Cellgro Mediatech, Herndon, VA), supplemented with $100 \mu \mathrm{g} / \mathrm{ml}$ penicillin-streptomycin (Cellgro Mediatech), $2 \mathrm{mM}$ L-glutamine (Cellgro Mediatech), and 10\% (v/v) FBS (Atlas Biologicals, Fort Collins, CO). The assay used a Vybrant cell adhesion assay kit (Molecular Probes Inc., Eugene, OR), based on the manufacturer's instructions. Briefly, TrHBMEC were seeded into wells of 96-well plates and were grown to confluence. MDA-231 and MDA-MET cells were harvested and treated with neuraminidase $\left(10 \mathrm{mU} / \mathrm{ml}, 37^{\circ} \mathrm{C}, 75 \mathrm{~min}\right)$ and then labeled with Calcein AM (Molecular Probes Inc.). Calcein AM-labeled, neuraminidase-treated and non-treated tumor cells were added to the confluent monolayer of TrHBMEC in serum-free medium and incubated for $2 \mathrm{~h}$ at $37^{\circ} \mathrm{C}$. After $2 \mathrm{~h}$ of incubation, non-adherent cells were removed by gentle washing with PBS. Then, $200 \mu 1$ PBS was added and fluorescence measured using Spectra Fluor fluorescence plate reader (Tecan,
Triangle park, NC). The percentage of adhesion was calculated using the following formula: $\{$ [Test(washed wells)-background]/[Maximum(unwashed wells)-background] $\}^{*} 100$.

Bone marrow stimulation of tumor cell proliferation. Bone marrow was harvested from the femurs of BALB/c mice as described (23). Mice were housed in an approved animal facility with protocols approved by the University of Arkansas for Medical Sciences Institutional Animal Care and Use Committee. Briefly, the right femur of each mouse was dissected free of soft tissue and cells were eluted from the femurs with $0.5 \mathrm{ml}$ of Hank's Balanced Salt Solution (HBSS; Invitrogen Corp., Grand Island, NY) through the medullary cavity. The eluted cell suspension was collected in $1.5 \mathrm{ml}$ sterile eppendorf tubes and irradiated for $5 \mathrm{~min}$ at 3000 rads. MDA-MET or MDA-231 cells were cultured in LGM-3 $(50 \mu \mathrm{l} /$ well) at a density of 5000 cells per well in 96-well culture plates for $24 \mathrm{~h}$ at $37^{\circ} \mathrm{C}$. After $24 \mathrm{~h}, 50 \mu \mathrm{l}$ of the solution eluted from the marrow was added to each well. In some experiments, bone marrow was centrifuged (300 g) and the supernatant separated was added to tumor cells. Tumor cells receiving $50 \mu 1$ of HBSS were used as negative controls. Cell growth was determined using the bromodeoxyuridine (BrdU) cell proliferation enzyme-linked immunosorbent assay (ELISA) colorimetric assay (Roche, Basel, Switzerland). BrdU was detected with BrdU-specific antibodies conjugated with peroxidase, as described in the product manual. Conversion of 3,3',5,5'-tetramethylbenzidine (TMB) into a colored reaction product was quantified by measuring the absorbance with an ELISA Reader (Elx808 Ultra Microplate Reader, Bio-Tek) at a wavelength of $450 \mathrm{~nm}$. Individual experiments were repeated a minimum of three times.

Extracellular matrix adhesion assay. Adhesion assays were performed in wells of Cytomatrix ${ }^{\mathrm{TM}}$ cell adhesion strips (Chemicon International, Temecula, CA) coated with human fibronectin, collagen I, collagen IV, or BSA as control (blank) in accordance with the manufacturer's instructions. Briefly, a cell suspension of $10^{5}$ cells $/ \mathrm{ml}$ was incubated with the wells of adhesion strips at $37^{\circ} \mathrm{C}$ for $1 \mathrm{~h}$ in a $\mathrm{CO}_{2}$ incubator. Nonadherent cells were washed off the plate with PBS with $\mathrm{Ca}$ and $\mathrm{Mg}$, and the adherent cells were stained with $0.2 \%$ crystal violet in $10 \%$ ethanol for $5 \mathrm{~min}$. Excess stain was washed off with PBS, and the cell-bound stain was solubilized in a buffer containing $0.1 \mathrm{M} \mathrm{NaH}_{2} \mathrm{PO}$ and $50 \%$ ethanol (1:1). The absorbance was determined at $570 \mathrm{~nm}$ using an automatic microplate reader (Elx808 Ultra Microplate Reader, Bio-Tek, Winooski, VT). The number of viable cells added to each well was determined using a CellTiter 96 Aqueous ${ }^{\circledR}$ kit (Promega, Madison, WI). The absorbance of bound cells was standardized relative to the number of cells in each assay. The mean absorbance value for wells coated with each ECM protein was divided by mean absorbance value of blank (wells coated with BSA) to generate an absorbance ratio.

Matrigel invasion assay. Matrigel (Becton-Dickinson, Franklin Lakes, NJ) was diluted to the desired concentration with ice-cold serum-free medium, placed in the upper chamber of $12-\mathrm{mm}$ transwells and incubated at $37^{\circ} \mathrm{C}$ for $30 \mathrm{~min}$ to allow Matrigel polymerization. Tumor cells were seeded onto 
Table I. Glycosyltransferases that are preferentially expressed on MDA-MET cells.

\begin{tabular}{|c|c|c|c|c|c|}
\hline Gene & $\begin{array}{c}\text { GenBank } \\
\text { accession no. }\end{array}$ & $\begin{array}{l}\text { Average intensity } \\
\text { of MDA- } 231\end{array}$ & $\begin{array}{l}\text { Average intensity } \\
\text { of MDA-MET }\end{array}$ & Ratio & t-test \\
\hline B4GALT1 & U10473 & 131.37 & 299.52 & 2.28 & 0.0021 \\
\hline B4GALT5 & AB004550 & 161.87 & 329.51 & 2.03 & 0.0003 \\
\hline FUT2 & D87942 & 201.19 & 1649.8 & 8.2 & 0.002 \\
\hline FUT3 & U27328 & 27.70 & 115.35 & 4.16 & 0.0003 \\
\hline GALNT2 & X85019 & 362.73 & 739.31 & 2.03 & 0.00033 \\
\hline GCNT1 & M97347 & 42.92 & 86.1 & 2.01 & 0.00022 \\
\hline HGNT-IV-H & AB024729 & 87.65 & 382.15 & 4.36 & 0.0021 \\
\hline POFUT1 & D80002 & 114.83 & 386.99 & 3.37 & 0.0003 \\
\hline ST3Gal IV/ST3Gal III & X74570 & 372.39 & 772.97 & 2.07 & 0.0012 \\
\hline ST6GalNAc II & U14550 & 144.59 & 292.07 & 2.02 & 0.00022 \\
\hline ST8Sia I & X77922 & 40.51 & 200.96 & 4.96 & 0.0003 \\
\hline ST8Sia III & AF004668 & 69.61 & 927.23 & 13.32 & 0.001 \\
\hline
\end{tabular}

Matrigel and incubated for $36 \mathrm{~h}$ at $37^{\circ} \mathrm{C}$. Non-migrating cells on the upper surface of the filters were then removed with a cotton swab. Cells that had migrated to the lower side were stained with Dif-Quick stain (IMEB, Inc., San Marcos, CA) and counted by microscopy. Baseline migration was determined by the number of cells migrating through the uncoated membrane. Invasion index is the proportion of cells that penetrate the Matrigel-coated membrane divided by the number of cells that migrate through the uncoated membrane (baseline migration).

\section{Results}

MDA-MET cells display increased levels of gycosyltransferases. As the first step in evaluating the surface glycosylation pattern of the variants, gene expression profiling was used to examine the expression levels of a group of glycosyltransferase genes involved in adding galactose, glucose, mannose, fucose, or sialic acid residues to cell surface proteins. Hierarchical cluster analysis of the microarray data (16) with high confidence showed that a number of glycosyltransferases were differentially expressed between MDA-231 and MDA-MET cells (Table I). We selected genes in MDA-MET cells that, based on Student's t-test, showed statistically significant increases in expression that were $>2$-fold higher than in MDA231 cells. The genes with a $>2$-fold increase in expression in MDA-MET cells included galactosyltransferase, fucosyltransferase, and sialyltransferase genes.

Galacotsyltransferase genes are responsible for producing Galß $(1,4)$ GlcNAc linkages (B4GALT1 and B4GALT5), and fucosyltransferase genes are responsible for adding fucose to GlcNAc in $(1,2)$ and $(1,3)$ linkages (FUT2 and -3) $(24,25)$. A GalNAc $O$-glycosylation gene (GALNT2) and $O$-glycan core 2 structure [Galß1-3(GlcNAc ß1-6)GalNAc] associated gene (GCNT1). GnT enzymes catalyze N-acetylglucosamine branching on asparagine-linked oligosaccharides of cell proteins. The gene encoding for mannosyl ( $\alpha-1,3-)$-glycoprotein
ß-1,4-N-acetyl-glucosaminyl-transferase (HGNT-IV-H) became significantly upregulated in MDA-MET.

$\mathrm{O}$-fucosylation is mediated by protein O-fucosyltransferase 1 (POFUT). This enzyme adds O-fucose to Notch receptors (26). $O$-fucose glycans exist on glycoproteins as either monosaccharides (Fuc-O-Ser/Thr), tetrasaccharides (NeuAc 2, 3/6Gal 1, 4GlcNAc 1, 3Fuc-O-Ser/Thr), or di- or trisaccharide intermediates in tetrasaccharide biosynthesis $(26,27)$.

In addition, many of the sialyltransferase genes encoding products responsible for adding sialic acid to galactose in $(2,3)$ and $(2,6)$ linkages (ST3Gal III, IV, and ST6GalNAcII) were also upregulated in MDA-MET cells. Notably, ST3GAL III and ST6GalNAcII are involved in the synthesis of the $\alpha 2,3-$ and $\alpha 2,6-$ Sia glycotopes on O-glycan chains and possibly on gangliosides (along with GALGT) (28). In the ST3Gal family, the ST3Gal I and II subfamilies exclusively use the type 3 oligosaccharide structure Galß1,3GalNAc-R, whereas the ST3Gal III, IV, V, and VI subfamilies use the oligosaccharide isomers Galß1 3/4Glc(NAc)-R. Enzymes of the ST8Sia family, which mediate the transfer of Neu5Ac residues in $\alpha 2,8$-linkage to other Neu5Ac residues found in glycoproteins and glycolipids, are observed in MDA-MET cells (29). Increased expression of the galactosyltransferase, fucosyltransferase, and sialyltransferase genes in MDA-MET cells also predicts that the synthesis of Lewis type-II structures (e.g., Lex, sLex, or LeY) is increased in these cells.

The bone colonizing variant MDA-MET displays altered cellsurface glycosylation. To focus our search for carbohydrate epitopes that differentiate MDA-231 from MDA-MET, anticarbohydrate antibodies and plant lectins were used to directly characterize the cell surface glycosylation pattern of both the parental MDA-231 and MDA-MET cell lines. Flow cytometry was used to investigate the carbohydrate structures decorating the surface of both cell lines. In this analysis using 15 different lectins and 4 carbohydrate-specific MAbs, five of the lectins and two of the antibodies revealed substantial differential 
A
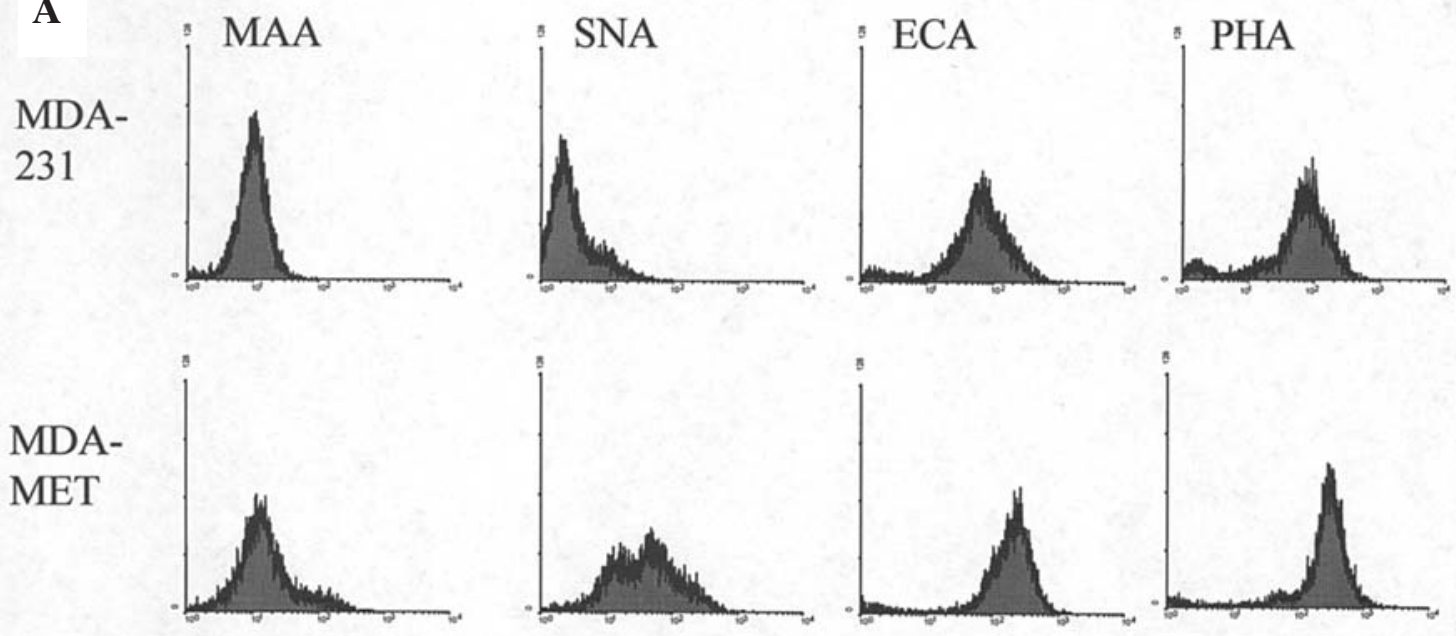
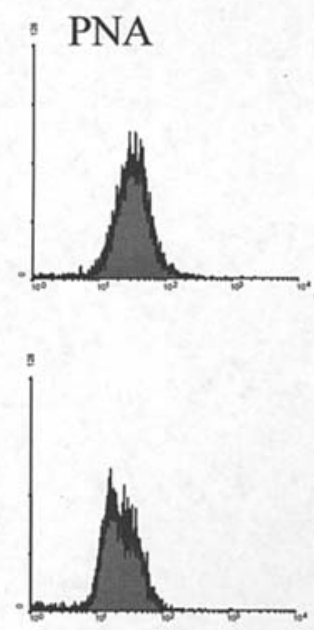

B

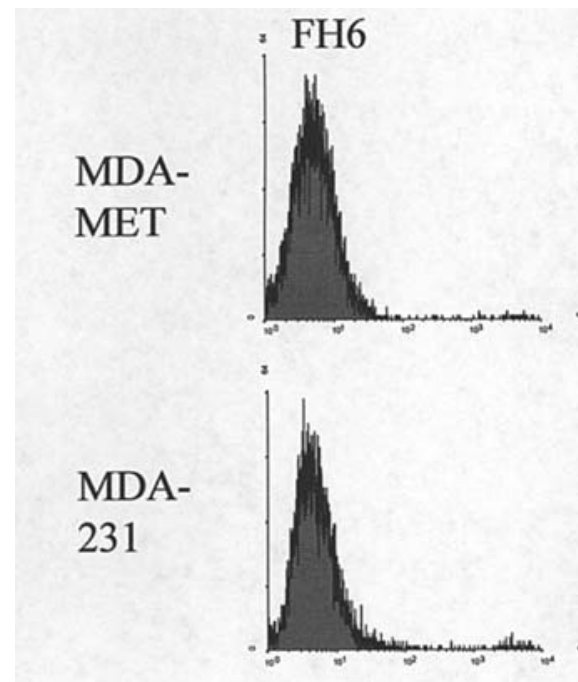

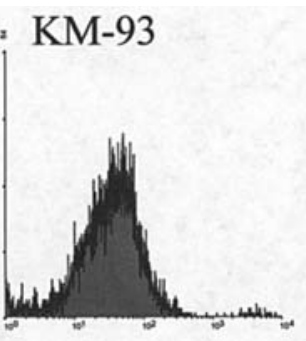

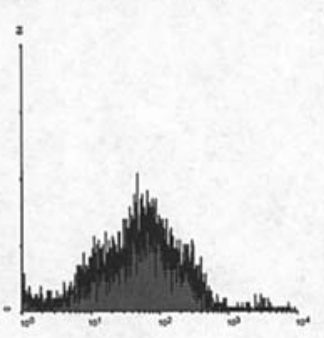

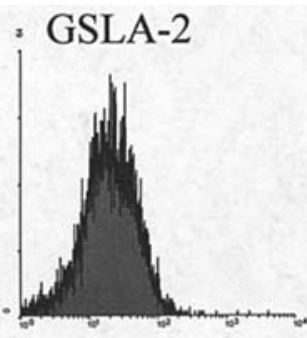

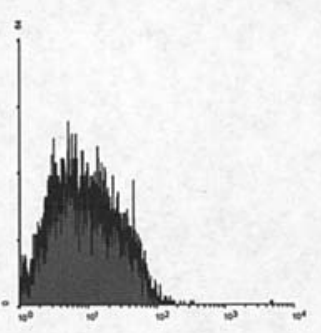

BR55-2
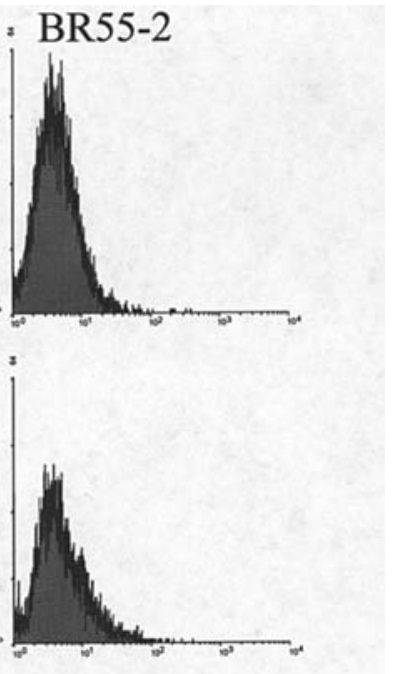

Figure 1. Lectin (A) and monoclonal antibody (B) binding profiles for MDA-MET and MDA-231 cells by flow cytometry. Five of fifteen lectins, whose reactivity is shown, displayed differential binding to MDA-MET and MDA-231. Cells of each tumor cell line were incubated with and allowed to bind to biotinylated lectins $\left(5 \mu \mathrm{g} / \mathrm{ml}, 0^{\circ} \mathrm{C}, 30 \mathrm{~min}\right)$. Binding was visualized by incubating with streptavidin-fluorescein (A). Monoclonal antibodies (10 $\left.\mu \mathrm{g} / \mathrm{ml}\right)$ were incubated with cells (on ice, $30 \mathrm{~min}$ ) before addition of fluorescein-conjugated goat anti-mouse immunoglobulin (B). Cells were then washed and fixed with paraformaldehyde before analysis by flow cytometry.

staining (Fig. 1). Profiling with SNA lectin demonstrates differential sialic acid binding specificity between the two cell lines (Fig. 1A). SNA staining was higher in MDA-MET cells than in MDA-231 cells, indicating a significant increase in the expression of sialic acid in 2,6 linkage with either Gal or GalNAc. MAA staining was only modestly higher in MDA-MET cells (Fig. 1A).

Consistent with the data generated by gene array analyses, the level of ECA staining was also higher in MDA-MET cells than in MDA-231 cells, indicating an increased amount of a Type 2 terminal $\mathrm{N}$-acetyllactosamine $(\operatorname{GalB}(1,4)$ GlcNAc) structure (Fig. 1A). This structure is commonly found in the antennae of N-linked and O-linked oligosaccharides and glycolipids (30). PHA, a lectin that reacts with complex sugar structures, such as $\operatorname{Gal}(1,4) \operatorname{GlcNAc}(1,2) \operatorname{Man}(31)$, also displayed enhanced reactivity with MDA-MET cells (Fig. 1A), and this is consistent with results of ECA binding. While the Type 2 structure is often sialylated in either 2,3 or 2,6 linkage, ECA will not bind either of the sialylated forms (30) suggesting that lactosaminic termini on MDA-MET cells remain unsubstituted despite higher global sialylation. In contrast, a decrease in the overall expression of $\mathrm{T}$ antigen was observed in MDA-MET cells, as measured by PNA staining (Fig. 1A). In addition, treatment of cells with neuraminidase resulted in a greater increase in PNA-reactive epitopes on MDA-MET cells than on MDA-231 cells (data not shown) suggesting that the PNA epitopes are more sialylated in MDA-MET.

The neolactoseries antigens, sLeX and sLeA, act as ligands for the selectin family of adhesion proteins that have been implicated in the metastatic spread of tumor cells (32). Therefore, we examined the expression of these important carbohydrate structures in MDA-MET and MDA-231 cells. Based on the gene array data, higher levels of LeX, sLeX, or LeY on MDA-MET cells than on MDA-231 cells were expected. Surprisingly, binding of the sLeX-specific mAb, KM93 (33), was higher in MDA-231 cells (Fig. 1B). An extended form of sLeX, which is reactive with $\mathrm{mAb}$ FH6, was displayed in equal proportions on both cell lines (Fig. 1B). Lotus lectin, specific 


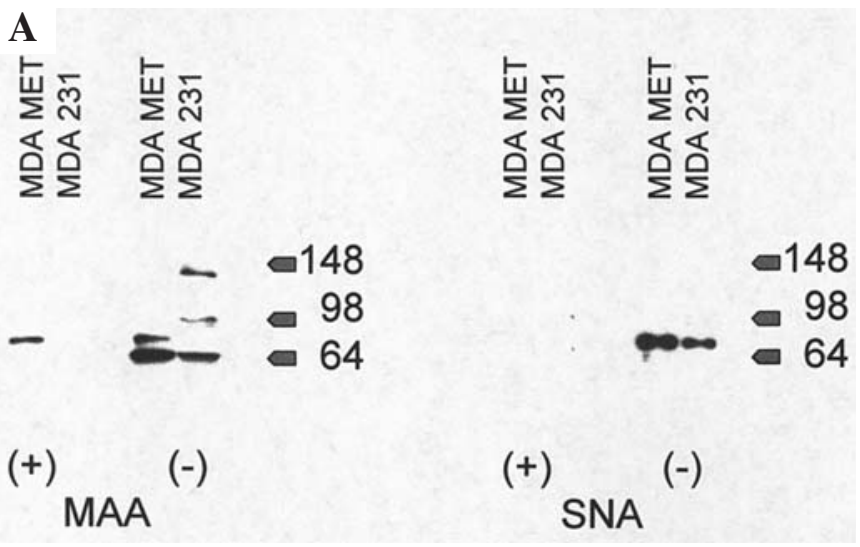

B

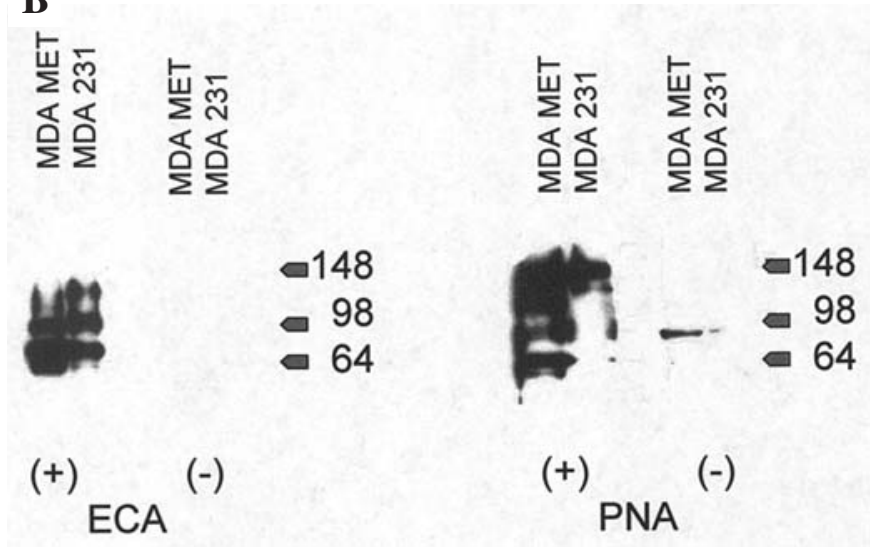

C

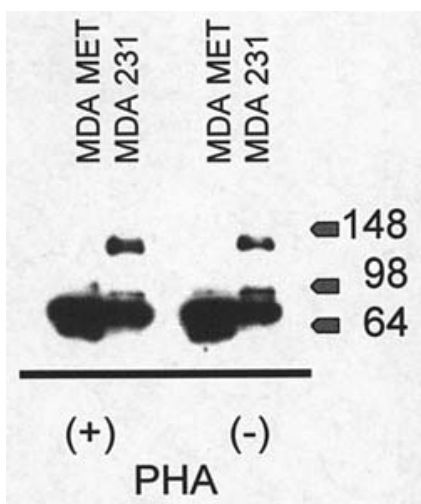

Figure 2. Lectin blot analysis of carbohydrate structures of MDA-MET and MDA-231 glycoproteins. Whole-cell lysates from both cell lines were prepared and separated by SDS-PAGE before electrophoretic transfer to PVDF membrane. The membranes were then either digested $(+)$ or mockdigested (-) with neuraminidase before being probed with the indicated biotin-conjugated lectins. Molecular weights $(\mathrm{kDa})$ are displayed on the right of each blot. Blots were probed either with (A) MAA and SNA, whose binding is sialic acid dependent; (B) ECL and PNA, whose binding is blocked by sialic acid; or (C) PHA, whose binding is unaffected by the presence or absence of sialic acid

for LeX and other fucosylated structures, did not differentiate between the two cell lines (data not shown). Binding of the sLeA-specific mAb, GSLA-2, was higher on MDA-MET than MDA-231 cells (Fig. 1B).

Lectin blot analysis of MDA-MET indicate a restricted set of molecular weight proteins common to both cell lines. To characterize the lectin reactive glycoprotein expression pattern, Western blots analyses with lectins either before or after neuraminidase digestion (Fig. 2) were performed. MDA-MET and MDA-231 cells were lysed, and equal amounts of protein $(10 \mu \mathrm{g})$ were separated by SDS-PAGE and then transferred to PVDF membranes. The membranes were either digested with neuraminidase or mock digested before they were probed with MAA, SNA, ECL, PHA, or PNA (Fig. 2). Interestingly, the lectins that displayed increased binding to MDA-MET (MAA, SNA, ECA, and PHA) as assessed by flow cytometry also appeared to recognize one or more of the same four protein bands $(130,98,80$, and $64 \mathrm{kDa})$ in either MDA-MET or MDA-231.

In MDA-MET cell lysates, a strong $80-\mathrm{kDa}$ band was resolved by SNA binding (Fig. 2A); this band appeared much weaker in MDA-231 lysates. The band disappeared after neuraminidase treatment, confirming $\alpha 2-6$ sialylation. MAA bound to bands at 130,98 , and $64 \mathrm{kDa}$ in MDA-231 lysates and to bands at 80 and $64 \mathrm{kDa}$ in MDA-MET lysates (Fig. 2A). After neuraminidase digestion, MAA bound only to the $80-\mathrm{kDa}$ band in MDA-MET lysates. This sialic acid-independent binding may be due to the presence of hemagglutinating isolectin (MAL-II or MAL) in the MAA preparation used; this protein has been shown to bind to 3-O-sulfated galactose (34). Alternatively, the leukoagglutinating isolectin (MAL-I or MAL) has been observed to bind in a sialic acid-independent manner when used in flow cytometry (34) and, therefore, might also do so during lectin blotting.

PNA also appears to bind to an $80-\mathrm{kDa}$ protein in MDAMET lysates in contrast to MDA-231 cells, suggesting that this protein displays the $\mathrm{T}$ antigen (Fig. 2B). The treatment of both MDA-MET and MDA-231 cell lysates with neuraminidase specifically uncovers many different protein bands (Fig. 2B). This is especially true for MDA-MET lysates, suggesting that these cells have more cryptic PNA sites uncovered by neuraminidase digestion than MDA-231 cells.

Prior to neuraminidase treatment, there is little or no ECA binding to either MDA-MET or MDA-231 lysates (Fig. 2B), suggesting that ECA binding to MDA-MET cells identified by flow cytometry may be lipid associated. After neuraminidase digestion, ECA binds to bands at 130,98 , and $80 \mathrm{kDa}$ in MDA-231 lysates and to bands at 98, 80, and $64 \mathrm{kDa}$ in MDA-MET lysates. Neuraminidase digestion uncovered more cryptic ECA structures (at 80 and $64 \mathrm{kDa}$ ) in the MDA-MET cell lysate than in the MDA-231 lysate.

PHA binds strongly to the $130-$ and $80-k D a$ bands but binds relatively weakly to the $98-\mathrm{kDa}$ band in MDA-231 lysates; in contrast, PHA binds almost exclusively to the 80and 64-kDa bands in MDA-MET cell lysates. Interestingly, neuraminidase treatment had no effect on the binding of PHA to its target glycoproteins in either MDA-MET or MDA-231 lysates, indicating again that these lactosaminic termini remain unsubstituted (Fig. 2C).

Because L-PHA, which preferentially recognizes B1-6 GlcNAc branches of tri- or tetraantennary sugar chains, binds to matriptase (35), the PHA reactive $64-\mathrm{kDa}$ band might be matriptase (35). To investigate this possibility, another series of Western blot experiments was performed. Since the human breast cancer cell line, MCF-7, has been shown to express matriptase (35), MCF-7 lysate was used as a positive control for matriptase expression in these experiments. Equal amounts of protein from the total cell lysates of MCF-7, MDA-MET, 


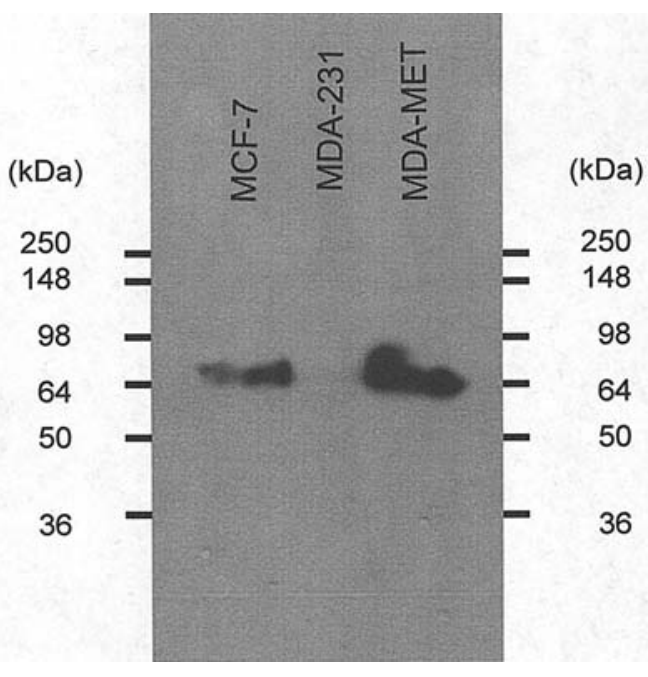

Figure 3. Matriptase is present in MDA-MET cells. Western blot analysis of matriptase was carried out using the same MDA-231 and MDA-MET total-cell lysates used in the lectin blots shown in Fig. 2 and an equal amount of total-cell lysate from MCF-7 (positive control). Matriptase was detected using polyclonal rabbit antibodies directed against human matriptase, followed by goat anti-rabbit IgG.

and MDA-231 cell lines were separated by SDS-PAGE and then transferred to PVDF membranes. The membranes were probed with an anti-matriptase rabbit polyclonal antibody, followed by treatment with horseradish peroxidase-conjugated anti-rabbit antibody and detection of chemiluminescence. The PHA reactive $64-\mathrm{kDa}$ band was positively identified as matriptase in both control MCF-7 and MDA-MET lysates (Fig. 3). The intensity of the matriptase band was significantly higher in MDA-MET lysates than in either MCF-7 or MDA-231 lysates. A similar pattern was seen with PHA binding, indicating that differential carbohydrate expression corresponds to differential protein expression.

The MDA-MET variant displayed heterotypic adhesion to human bone-marrow-derived endothelial cells. The expression of $\mathrm{T}$ antigen is proposed to improve bone metastasis via enhancement of the adhesion of tumor cells to human bone marrow endothelial cells (9). The PNA flow cytometry and Western blot analyses imply a restricted expression of $\mathrm{T}$ antigen on the surface of MDA-MET cells. Because of the decreased expression of the T antigen on MDA-MET cells, the ability of the two cell lines to adhere to a monolayer of TrHBMEC (20-22) was evaluated. The results of these experiments (Fig. 4A) demonstrate that MDA-MET cells adhere to TrHBMEC at three times the level of MDA-231 cells. Interestingly, while the Western blot experiments suggest that treating MDA-MET cells with neuraminidase uncovers more $\mathrm{T}$ antigens, this treatment does not appear to impact endothelial cell adhesion (Fig. 2B). This result implies a unique role for the $80-\mathrm{kDa}$ protein, carrying non-sialylated $\mathrm{T}$ antigen, in adhesion. Treatment of MDA-MET cells with tunicamycin, an inhibitor of N-linked glycosylation, did not affect endothelial cell binding (data not shown), suggesting that the interactions between the two cell types are mediated by O-linked $\mathrm{T}$ antigen or perhaps by as yet undefined Galß1,3GalNAc lipid constituents.
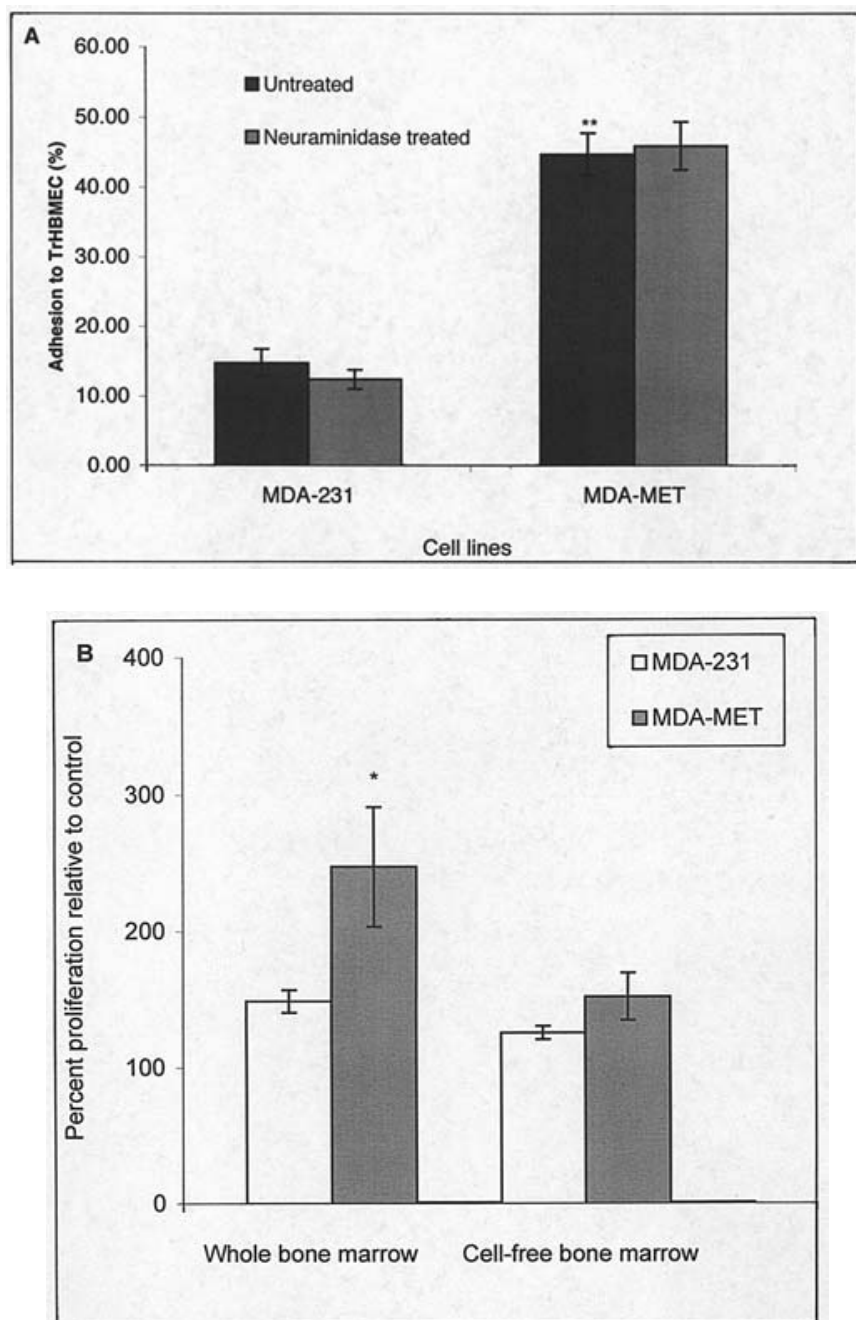

Figure 4. MDA-MET cells displayed adherence to human bone marrow endothelial cells and cell proliferation stimulated by bone marrow cells was mediated by cell-cell contact. (A) $2 \times 10^{4}$ TrHBMEC were seeded in wells of a 96-well plate. After forming monolayer, medium was replaced with serum-free medium containing Calcein AM-labeled tumor cells. Cells $\left(1.5 \times 10^{5}\right)$ were added to the monolayer in each well. For each cell variant, half of the wells' cells were treated with neuraminidase before adding cells. Results show averages for the adhesion based on 12 replications for each treatment. ${ }^{* *}$ Statistically significant at $\mathrm{P}<0.001$ as compared with untreated MDA-231 cells using Student's t-test. (B) MDA-231 or MDA-MET cells were cultured in 96-well culture plates at a density of 5000 cells per well. After $24 \mathrm{~h}, 50 \mu \mathrm{l}$ of either the whole bone marrow wash or the cell-free bone marrow supernatant were added to the cells; tumor cells receiving $50 \mu 1$ of HBSS were used as negative controls. Cell proliferation was measured by BrdU incorporation into genomic DNA. Error bars show \pm SEM. *Statistically significant as compared with MDA-231 cells $(\mathrm{P}<0.001)$.

Next, the interaction between MDA-MET or MDA-231 cells and the host bone marrow was examined. In these experiments, the effects of direct cell-cell contact or the secretion of tumor-derived factors on MDA-MET proliferation were examined. The long bones of Balb/c mice were flushed with HBSS; $50 \mu 1$ of this solution containing marrow cells and soluble factors was added to MDA-MET or MDA-231 cells cultured in LGM-3 medium (Fig. 4B). Cell growth was measured using the BrdU cell proliferation ELISA colorimetric assay (Roche, Basel, Switzerland). After a 24-h incubation of MDA-MET and MDA-231 cells in whole bone marrow eluate, cell proliferation was measured and compared with the 
MDA-231 cells
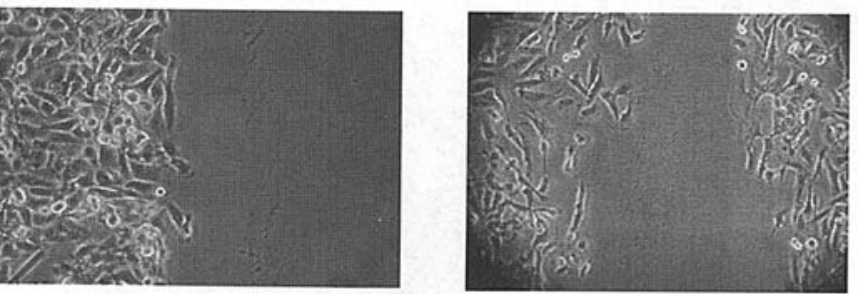

MDA-MET cells
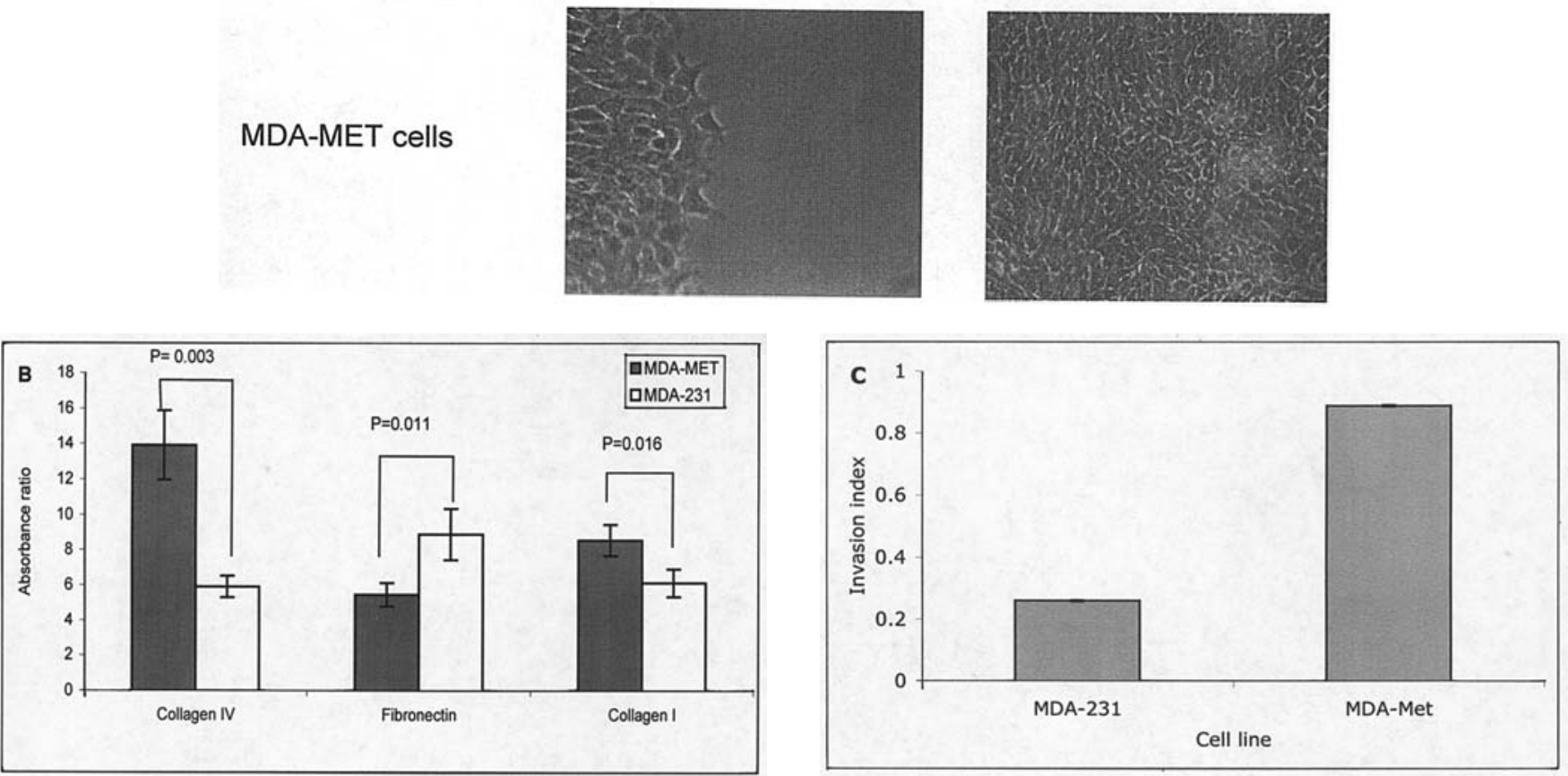

Figure 5. Tumor cell motility, adhesion and invasion of ECM proteins. (A) A wound healing assay performed with MDA-231 and MDA MET cell lines. Cells were seeded in 24-well culture plates until reaching a confluent state. After monolayers of the cells were achieved, a wounded cell-free area was made in the center of the monolayer using a plastic pipette tip. Migration of cells following 'wounding' of the cell monolayer was monitored by photography at 24 and $72 \mathrm{~h}$ after wounding. (B) Adhesion assays were performed in wells of the cytomatrix adhesion strips coated with either human fibronectin, collagen I, collagen IV, or BSA as negative control (blank). Single-cell suspensions $\left(10^{5} \mathrm{cells} / \mathrm{ml}\right)$ were incubated in the wells at $37^{\circ} \mathrm{C}$ for $1 \mathrm{~h}$ in a $\mathrm{CO}_{2}$ incubator. Non-adherent cells were washed off the wells and the adherent cells were stained. Excess stain was washed off, the cell-bound stain was solubilized, and the absorbance was measured at $570 \mathrm{~nm}$. The absorbance ratio for each ECM protein to BSA was calculated and presented. Error probabilities calculated by Student's t-test. (C) Tumor cells were seeded onto Matrigel and incubated for $36 \mathrm{~h}$ at $37^{\circ} \mathrm{C}$. After $36 \mathrm{~h}$, non-migrating cells on the upper surface of each filter were removed with a cotton swab; cells that had migrated to the lower side were stained and counted by microscopy. Invasion index is the proportion of cells that penetrated the Matrigel-coated membrane divided by the number of cells that migrated through the uncoated membrane. Values equal means $\pm \mathrm{SD}$ of three replications.

respective controls (cells incubated in HBSS). A significant increase in relative proliferation for MDA-MET compared to MDA-231 cells (Fig. 4B) was observed. In contrast, when MDA-MET or MDA-231 cells were grown in the presence of cell-free bone marrow, both cell lines were stimulated to proliferate to the same extent (Fig. 4B). Over the 24-h period, proliferation of the two cell lines in the control medium was similar (data not shown), indicating that neither cell line was preferentially stimulated by the medium alone. These data indicate that preferential proliferation of MDA-MET cells in bone marrow is influenced by cell-cell contact with bone marrow cells and not by factors shed into the bone marrow microenvironment.

The MDA-MET variant displayed enhanced motility and an altered ECM adhesion. In general, increased amounts of sialylation products on cell surfaces are suggested to affect homotypic binding, which should afford increases in cell motility. To determine whether this is the case for MDA-MET cells, homotypic binding and motility in this cell line was compared with the parent MDA-231 cell line. To assess homotypic adhesion, cell motility was evaluated using wound-healing assays (Fig. 5A). Cells were cultured in 6-well plates and, at confluence, a 'wounded' cell-free area was made in the center of the monolayer. Migration of cells following 'wounding' of the cell monolayer was monitored. At $72 \mathrm{~h}$ after scraping, MDA-MET cells completely covered the scratched surface of the dish, while the MDA-231 cells did not.

It is purported that sialylation of integrin structures affects binding to ECM proteins; this may impact the dormancy of tumor cells in the bone because fibronectin binding is proposed to inhibit apoptotic signals, thereby prolonging tumor cell 
survival in the bone (15). We observed that the absorbance ratio of MDA-231 breast cancer cells bound to fibronectin $(8.91 \pm 1.45)$ was higher than those binding to collagen IV or collagen I (5.90 \pm 0.61 and $6.13 \pm 0.78$, respectively) (Fig. 5B), indicating a preference for ECM protein binding. Conversely, MDA-MET cells display significantly higher adherence to collagen IV (absorbance ratio of MDA-MET vs MDA-231 cells was 13.91 vs $5.90, \mathrm{P}<0.003$ ) and significantly lower adherence to fibronectin (absorbance ratio of MDA-MET vs MDA-231 cells was 5.47 vs 8.91, $\mathrm{P}<0.011$ ) (Fig. 5B).

In Matrigel invasion assays, MDA-MET cells also displayed a significantly higher invasion index than MDA-231 cells (Fig. 5C). This may be related to the expression of matriptase on MDA-MET cells because increased expression of matriptase is known to enhance invasion on Matrigel. Our data indicate that the cell-surface molecules important in tumor cell interaction with ECM factors may influence mechanisms associated with late-stage events in metastasis; however, the molecular basis of these interactions is still poorly understood.

\section{Discussion}

Distant metastasis is the leading cause of death related to breast cancer and other solid tumors. Evidence of persistent, isolated tumor cells in bone marrow from patients with breast carcinoma indicates an increased risk for subsequent recurrence (36). The specific molecules and mechanism(s) that allow breast cancer cells to take up residence and thrive in the bone marrow microenvironment remain largely unknown, although many candidates have been identified (18,37-39). Gene expression profiles suggest that primary hematogenous dissemination of breast tumor cells is a selective process (40-42). It is likely that some functional consequences of upregulated genes are associated with the glycosylation status of the encoded products.

Mechanistically, carbohydrate structures affect the metastatic process by participating in both homotypic binding, which facilitates the aggregation of cancer cells, and heterotypic adhesion, which allows cancer cells to bind to the microvascular endothelium $(9,10)$. Therefore, together with differential gene expression, the emergence of new carbohydrate-mediated heterotypic and homotypic adhesive interactions during postintravasational stages may impact establishing secondary lesions in distant tissue and organs. To gain a better understanding of the functional relevance of the relationship between bone metastasis and cell surface glycoproteins, particularly specific carbohydrate epitopes, we are focusing on defining changes in glycosylation patterns associated with osteotropic versus non-osteotropic phenotypes. In vivo selection offers a useful approach to further examine selected subclones of malignant cells that give rise to osteolytic metastases. Concentrating on a subpopulation and its genetic parental cell line, which displays a different tumorigenic and osteolytic phenotype, provides insight into the strategies tumor cells use to interact with the bone marrow microenvironment. Our gene profiling experiments suggest that, in addition to increased IL-8 secretion $(16,18)$, the bone colonizing phenotype of MDA-MET also involves an increase in glycoconjugates decorated with several carbohydrate forms that include sialic acid, the more complex $\operatorname{Gal} \beta(1,4) \operatorname{GlcNAc} \beta(1,2$ or 1,6$)$ Man structure, and sLeA. Based on these results, several possible mechanisms that might affect tumor cell dissemination and bone colonization can be postulated.

First, aberrant sialylation in cancer cells is believed to be a characteristic feature associated with malignant properties that include invasiveness and metastatic potential (43). Increased sialylation can reduce homotypic binding of tumor cells, contributing to cell disaggregation and, presumably, increased cell migration (44). The notion of passive metastatic dissemination as a consequence of impaired cell-matrix adhesion and tumor tissue disaggregation has been proposed (45). We observed an increase in the migration properties of MDA-MET cells, which we attribute to an increase in sialylation; however, this alone is probably not sufficient to define a mechanism for bone metastases. Interestingly, increases in sialylation are associated with tumor progression in murine models of liver metastases of colon carcinomas (46-48). Interestingly, in addition to the bone tumors observed following intercardiac injection of MDA-MET cells, micrometastases can be detected by PCR in the liver, but not in the lung and kidney, suggesting that there may be yet common endogenous receptors for sialylated ligands that contribute to organ tropism (our unpublished data). However, sialylation does not directly affect the cell-cell contact (adhesion) between MDA-MET cells and the bone marrow endothelium.

Secondly, expression of certain terminal glycosyltransferases may be associated with cells with a higher potential for bone colonization. Expression analyses with cDNA arrays show that profiles from primary tumors from bone marrowpositive patients are distinct from those of bone marrownegative patients. This suggests that primary hematogenous dissemination of breast tumor cells exists as a selective process associated with a specific molecular signature that is mainly characterized by suppression of gene expression (42). The Thomsen-Friedenreich antigen has been shown to be a tumor specific antigen in breast cancer and is an important marker of aggressiveness (9). Recent results demonstrate that the $\mathrm{T}$ antigen is expressed on disseminated tumor cells in the bone marrow of breast cancer patients (49). It is likely that the results described here correlate with $\mathrm{T}$ antigen binding to bone endothelium cells and that this antigen can be differentially expressed from the parental tumor cell line. Regarding the role of PNA and SNA reactive epitopes in tumor dissemination and bone metastasis and that an $80-\mathrm{kDa}$ protein is found to carry both epitopes, it is tempting to speculate that this protein plays an important role in the bone colonizing feature of MDA-MET cells.

Thirdly, sialylation of tumor cells has been linked to ECM-binding proteins and invasive ability $(11,12,50)$. Mechanistically, sialylation may dictate differences in bonecolonizing versus bone-dormant cells. It has been suggested that breast cancer cells that are dormant in the bone prefer binding to fibronection, which functions as an anti-apoptotic signal (15). The integrins $\alpha 1 \beta 1$ and $\alpha 2 \beta 1$ are cell-surface receptors for collagen IV and collagen $\mathrm{I}$, and $\beta 1$ is also responsible for fibronectin binding. Early studies showed that sialylation of the B1-chain is associated with decreased fibronectin binding (12). Because we observed a decrease in fibronectin binding of MDA-MET cells, it is highly likely that the integrin $B 1$ chain is affected by 2,6 sialylation. However, 
a decrease in fibronectin binding and increase in Matrigel invasiveness has also been correlated with increased expression in $\beta 1,6$ GlcNAc branching on the cell surface $(13,14)$.

Fourth, we observed that, while a high proportion of cell surface lactosaminic termini have been sialylated in MDAMET cells, there are still some termini that are not. The carbohydrate structure recognized by the lectin L-PHA, which has been used to identify glycoproteins (51). Matriptase is a particularly interesting glycoprotein that plays important roles in cell migration, degradation of ECM, and activation of single chain urokinase-plasminogen activator and hepatocyte growth factor. In breast carcinoma, matriptase expression is associated with poor patient outcome (52). Addition of $B 1,6-$ branched oligosaccharides to matriptase plays a pivotal role in the glycoprotein's stability and resistance to proteolysis by trypsin (35). Lectin blot analysis revealed that matriptase is highly expressed in MDA-MET cells and, under identical conditions, is undetectable in MDA-231 cells. Likewise, we observed selective expression of the PNA epitope, which may lend to binding to bone marrow endothelium cells. ST6GalNAcII is elevated in our array analysis which preferentially sialylates the $\mathrm{T}$ antigen (53). Global expression of the PNA epitope does not contribute to bone marrow endothelium cell binding as neuraminidase-treated cells did not display enhanced adhesion to TrHBMEC.

In conclusion, it is evident that the collective interpretation of multiple molecular markers is required to fully understand the formation of secondary osteolytic bone tumors from breast and other carcinomas. Changes in the glycomic profile that accompany tumor progression provide critical insight into the molecules and mechanism(s) that define the aggressive tumor phenotype. Our observations further support the concept that altering the glycan pattern modifies the biological features of cancer cells. Identification of glycomic profiles on tumor cells that colonize particular organs would provide a structure/ function viewpoint on the role played by glycosylation of specific proteins and lipids.

\section{Acknowledgements}

This work was supported in part by NIH grant CA089480 (TKE) and by the Breast Cancer Research Program of the University of Arkansas (LJS).

\section{References}

1. Braun S and Pantel K: Biological characteristics of micrometastatic cancer cells in bone marrow. Cancer Metastasis Rev 18: 75-90, 1999.

2. Chambers AF, Groom AC and MacDonald IC: Dissemination and growth of cancer cells in metastatic sites. Nat Rev Cancer 2: 563-572, 2002.

3. Gassmann P, Enns A and Haier J: Role of tumor cell adhesion and migration in organ-specific metastasis formation. Onkologie 27: 577-582, 2004.

4. Kawaguchi T: Cancer metastasis: characterization and identification of the behavior of metastatic tumor cells and the cell adhesion molecules, including carbohydrates. Curr Drug Targets Cardiovasc Haematol Disord 5: 39-64, 2005.

5. Hakomori S: Tumor-associated carbohydrate antigens defining tumor malignancy: basis for development of anti-cancer vaccines. Adv Exp Med Biol 491: 369-402, 2001.

6. Kannagi R, Izawa M, Koike T, Miyazaki K and Kimura N: Carbohydrate-mediated cell adhesion in cancer metastasis and angiogenesis. Cancer Sci 95: 377-384, 2004.
7. Al-Mehdi AB, Tozawa K, Fisher AB, Shientag L, Lee A and Muschel RJ: Intravascular origin of metastasis from the proliferation of endothelium-attached tumor cells: a new model for metastasis. Nat Med 6: 100-102, 2000.

8. McMahon RF, McWilliam LJ, Clarke NW and George NJ: Altered saccharide sequences in two groups of patients with metastatic prostatic carcinoma. Br J Urol 74: 80-85, 1994.

9. Khaldoyanidi SK, Glinsky VV, Sikora L, et al: MDA-MB435 human breast carcinoma cell homo- and heterotypic adhesion under flow conditions is mediated in part by ThomsenFriedenreich antigen-galectin-3 interactions. J Biol Chem 278: 4127-4134, 2003

10. Glinsky VV, Glinsky GV, Rittenhouse-Olson $\mathrm{K}$, et al: The role of Thomsen-Friedenreich antigen in adhesion of human breast and prostate cancer cells to the endothelium. Cancer Res 61: 4851-4857, 2001.

11. Lin S, Kemmner W, Grigull S and Schlag PM: Cell surface alpha 2,6 sialylation affects adhesion of breast carcinoma cells. Exp Cell Res 276: 101-110, 2002.

12. Veiga SS, Chammas R, Cella N and Brentani RR: Glycosylation of beta-1 integrins in B16-F10 mouse melanoma cells as determinant of differential binding and acquisition of biological activity. Int J Cancer 61: 420-424, 1995.

13. Guo HB, Zhang QS and Chen HL: Effects of H-ras and v-sis overexpression on $\mathrm{N}$-acetylglucosaminyltransferase $\mathrm{V}$ and metastasis-related phenotypes in human hepatocarcinoma cells. J Cancer Res Clin Oncol 126: 263-270, 2000

14. Guo HB, Zhang Y and Chen HL: Relationship between metastasisassociated phenotypes and N-glycan structure of surface glycoproteins in human hepatocarcinoma cells. J Cancer Res Clin Oncol 127: 231-236, 2001.

15. Korah R, Boots $M$ and Wieder R: Integrin alpha5beta1 promotes survival of growth-arrested breast cancer cells: an in vitro paradigm for breast cancer dormancy in bone marrow. Cancer Res 64: 4514-4522, 2004.

16. Bendre MS, Gaddy-Kurten D, Mon-Foote T, et al: Expression of interleukin 8 and not parathyroid hormone-related protein by human breast cancer cells correlates with bone metastasis in vivo. Cancer Res 62: 5571-5579, 2002.

17. Le Marer N and Stehelin D: High alpha-2,6-sialylation of Nacetyl-lactosamine sequences in ras-transformed rat fibroblasts correlates with high invasive potential. Glycobiology 5: 219-226, 1995.

18. Bendre M, Gaddy D, Nicholas RW and Suva LJ: Breast cancer metastasis to bone: it is not all about PTHrP. Clin Orthop 415 (suppl): S39-S45, 2003.

19. Dudoit S, Gentleman RC and Quackenbush J: Open source software for the analysis of microarray data. Biotechniques (suppl): 45-51, 2003.

20. Rafii S, Shapiro F, Rimarachin J, et al: Isolation and characterization of human bone marrow microvascular endothelial cells: hematopoietic progenitor cell adhesion. Blood 84: 10-19, 1994.

21. Schweitzer CM, van der Schoot CE, Drager AM, et al: Isolation and culture of human bone marrow endothelial cells. Exp Hematol 23: 41-48, 1995.

22. Schweitzer KM, Vicart P, Delouis C, et al: Characterization of a newly established human bone marrow endothelial cell line: distinct adhesive properties for hematopoietic progenitors compared with human umbilical vein endothelial cells I. Lab Invest 76: 25-36, 1997.

23. Gaddy-Kurten D, Coker JK, Abe E, Jilka RL and Manolagas SC: Inhibin suppresses and activin stimulates osteoblastogenesis and osteoclastogenesis in murine bone marrow cultures. Endocrinology 143: 74-83, 2002.

24. Amado M, Almeida R, Schwientek T and Clausen H: Identification and characterization of large galactosyltransferase gene families: galactosyltransferases for all functions. Biochim Biophys Acta 1473: 35-53, 1999.

25. Javaud C, Dupuy F, Maftah A, Julien R and Petit JM: The fucosyltransferase gene family: an amazing summary of the underlying mechanisms of gene evolution. Genetica 118 : 157-170, 2003.

26. Wang Y, Shao L, Shi S, et al: Modification of epidermal growth factor-like repeats with $\mathrm{O}$-fucose. Molecular cloning and expression of a novel GDP-fucose protein O-fucosyltransferase. J Biol Chem 276: 40338-40345, 2001.

27. Moloney DJ, Shair LH, Lu FM, et al: Mammalian Notch1 is modified with two unusual forms of O-linked glycosylation found on epidermal growth factor-like modules. J Biol Chem 275: $9604-9611,2000$. 
28. Dall'Olio F and Chiricolo M: Sialyltransferases in cancer. Glycoconj J 18: 841-850, 2001.

29. Angata K and Fukuda M: Polysialyltransferases: major players in polysialic acid synthesis on the neural cell adhesion molecule. Biochimie 85: 195-206, 2003.

30. Debray H, Montreuil J, Lis H and Sharon N: Affinity of four immobilized Erythrina lectins toward various N-linked glycopeptides and related oligosaccharides. Carbohydr Res 151: $359-370,1986$

31. Hammarstrom S, Hammarstrom ML, Sundblad G, Arnarp J and Lonngren J: Mitogenic leukoagglutinin from Phaseolus vulgaris binds to a pentasaccharide unit in N-acetyllactosamine-type glycoprotein glycans. Proc Natl Acad Sci USA 79: 1611-1615, 1982.

32. Takada A, Ohmori K, Yoneda T, et al: Contribution of carbohydrate antigens sialyl Lewis A and sialyl Lewis X to adhesion of human cancer cells to vascular endothelium. Cancer Res 53: 354-361, 1993.

33. Dohi T, Nemoto T, Ohta S, et al: Different binding properties of three monoclonal antibodies to sialyl $\mathrm{Le}(\mathrm{x})$ glycolipids in a gastric cancer cell line and normal stomach tissue. Anticancer Res 13: 1277-1282, 1993

34. Bai X, Brown JR, Varki A and Esko JD: Enhanced 3-O-sulfation of galactose in Asn-linked glycans and Maackia amurensis lectin binding in a new Chinese hamster ovary cell line. Glycobiology 11: 621-632, 2001

35. Ihara S, Miyoshi E, Nakahara S, et al: Addition of beta1-6 GlcNAc branching to the oligosaccharide attached to Asn 772 in the serine protease domain of matriptase plays a pivotal role in its stability and resistance against trypsin. Glycobiology 14: 139-146, 2004

36. Janni W, Rack B, Schindlbeck C, et al: The persistence of isolated tumor cells in bone marrow from patients with breast carcinoma predicts an increased risk for recurrence. Cancer 103: 884-891, 2005

37. Yoneda $\mathrm{T}$ and Hiraga T: Crosstalk between cancer cells and bone microenvironment in bone metastasis. Biochem Biophys Res Commun 328: 679-687, 2005.

38. Horak CE and Steeg PS: Metastasis gets site specific. Cancer Cell 8: 93-95, 2005.

39. Minn AJ, Kang Y, Serganova I, et al: Distinct organ-specific metastatic potential of individual breast cancer cells and primary tumors. J Clin Invest 115: 44-55, 2005.

40. Pantel $\mathrm{K}$ and Woelfle U: Micrometastasis in breast cancer and other solid tumors. J Biol Regul Homeost Agents 18: 120-125, 2004.

41. Gangnus R, Langer S, Breit E, Pantel K and Speicher MR: Genomic profiling of viable and proliferative micrometastatic cells from early-stage breast cancer patients. Clin Cancer Res 10: 3457-3464, 2004.
42. Woelfle U, Cloos J, Sauter G, et al: Molecular signature associated with bone marrow micrometastasis in human breast cancer. Cancer Res 63: 5679-5684, 2003.

43. Miyagi T, Wada T, Yamaguchi K and Hata K: Sialidase and malignancy: A minireview. Glycoconj J 20: 189-198, 2004.

44. Bosch J, Brossmer R, Kemmner W and Schlag P: Preparation and characterization of differently aggregated colorectal carcinoma cell subpopulations from surgical specimens. Cancer Detect Prev 22: 319-329, 1998

45. Cavallaro U and Christofori G: Cell adhesion in tumor invasion and metastasis: loss of the glue is not enough. Biochim Biophys Acta 1552: 39-45, 2001.

46. Nemoto-Sasaki Y, Mitsuki M, Morimoto-Tomita M, Maeda A, Tsuiji $\mathrm{M}$ and Irimura T: Correlation between the sialylation of cell surface Thomsen-Friedenreich antigen and the metastatic potential of colon carcinoma cells in a mouse model. Glycoconj J 18: 895-906, 2001.

47. Bresalier RS, Rockwell RW, Dahiya R, Duh QY and Kim YS: Cell surface sialoprotein alterations in metastatic murine colon cancer cell lines selected in an animal model for colon cancer metastasis. Cancer Res 50: 1299-1307, 1990.

48. Pousset D, Piller V, Bureaud N, Monsigny M and Piller F: Increased alpha2,6 sialylation of $\mathrm{N}$-glycans in a transgenic mouse model of hepatocellular carcinoma. Cancer Res 57: 4249-4256, 1997.

49. Schindlbeck C, Jeschke U, Schulze S, et al: Characterisation of disseminated tumor cells in the bone marrow of breast cancer patients by the Thomsen-Friedenreich tumor antigen. Histochem Cell Biol 123: 631-637, 2005.

50. Casey RC, Oegema TR Jr, Skubitz KM, Pambuccian SE, Grindle SM and Skubitz AP: Cell membrane glycosylation mediates the adhesion, migration, and invasion of ovarian carcinoma cells. Clin Exp Metastasis 20: 143-152, 2003.

51. Suzuki O, Nozawa Y, Kawaguchi T and Abe M: Alpha-2,6sialylation of L-PHA reactive oligosaccharides and expression of $\mathrm{N}$-acetylglucosaminyltransferase $\mathrm{V}$ in human diffuse large $\mathrm{B}$ cell lymphoma. Oncol Rep 10: 1759-1764, 2003.

52. Kang JY, Dolled-Filhart M, Ocal IT, et al: Tissue microarray analysis of hepatocyte growth factor/Met pathway components reveals a role for Met, matriptase, and hepatocyte growth factor activator inhibitor 1 in the progression of node-negative breast cancer. Cancer Res 63: 1101-1105, 2003.

53. Marcos NT, Pinho S, Grandela C, et al: Role of the human ST6GalNAc-I and ST6GalNAc-II in the synthesis of the cancerassociated sialyl-Tn antigen. Cancer Res 64: 7050-7057, 2004. 